\title{
Pentingnya Implementing Legislationkonvensi Anti Penyiksaan 1984 (Convention Against Torture) Kedalam Hukum Nasional Indonesia
}

\author{
Ahmad Adi Fitriyadi, Fikry Latukau \\ ahmad.fitriyadi5395@gmail.com, fikry18001@mail.unpad.ac.id
}

Mahasiswa Magister Ilmu Hukum Program Kekhususan Hukum Internasional dan Hukum Pidana, Universitas Padjadjaran, Angkatan 2018 ${ }^{12}$

\begin{abstract}
Abstrak
Persoalan tindak pidana Penyiksaan adalah masalah yang sudah sejak lama terjadi di negara Indonesia sejak zaman Orde Baru hingga detik ini.Banyak kasus yang terjadi bahkan hingga akhir tahun 2019 dan para pelakunya tidaklah kunjung diadili.Hal ini disebabkan tidak adanya aturan hukum pidana nasional Indonesia yang mengatur tersendiri terkait tindakan Penyiksaan. Padahal Indonesia merupakan negara peserta pada Convention against Torture and Other Cruel, Inhuman or Degrading Treatment or Punishment (CAT) atau Konvensi Anti Penyiksaan 1984 dan telah diratifikasi ke dalam Undang-Undang No.5 Tahun 1998. Namun, karena konvensi ini bersifat NonSelf Executing, maka perlu untuk dilakukan Implementing Legislation ke dalam hukum nasional Indonesia untuk diundangkan ke dalam hukum nasional Indonesia tersendiri terkait tindak pidana Penyiksaan, sebab tindakan Penyiksaan merupakan bagian dari kejahatan internasional yang mengancam masyarakat internasional, maka aturan hukum tersebut didasarkan pada Asas Yurisdiksi Universal.
\end{abstract}

Kata Kunci : Penyiksaan, Implementing Legislation, Asas Yurisdiksi Universal.

\section{Abstract}

Problem of Torture act is the issue which has happened since long time ago in Indonesia. It has been happening since New Orde regime until this moment. There are a lot of cases which happened even during in 2019 and the perprators have not been prosecuted because it has not been regulated about Torture act in Indonesian law. Indonesia, however, is a State Party of Convention against Torture and Other Cruel, Inhuman or Degrading Treatment or Punishment (CAT) 1984 and has ratified it to the Law No.5 Year 1998. Because the characteristic of this convention is NonSelf Executing, it must be done Implementing Legislation to be regulated in Indonesian law and has regulation concerning Torture as criminal act. Torture act is a part of international crime which threaten international society, so the regulation about it based on Universal Jurisdiction Principle.

Keywords : Torture, Implementing Legislation, Convention against Torture (CAT) 1984, Universal Jurisdiction Principle. 


\section{A. PENGANTAR}

Dalam kehidupan sosial ini, kita sering dihadapkan kepada masalah yang berkaitan dengan pelanggaran Hak Asasi Manusia (HAM).Pelanggaran HAM tersebut mengarah pada persoalan tindak pidana.Pelaku di dalam masyarakat yang melakukan tindak pidana pasti dijatuhkan hukuman pidana kepada pelaku sesuai dengan hukum pidana yang berlaku di wilayahnya.Pelanggaran-pelanggaran

HAM tersebut diantaranya disebabkan oleh adanya pembunuhan, pencurian, penghinaan, pemerkosaan, penganiayaan, korupsi, dan lain sebagainya.Tindakan-tindakan tersebut di Indonesia telah diatur di dalam Kitab Undang-Undang Hukum Pidana (KUHP) maupun undang-undang yang mengatur terkait tindak pidana khusus.

Kemudian, terdapat satu
pelanggaran HAM yangh justru
dilakukan oleh pihak yang berkaitan
erat dengan negara.Pelanggaran HAM
ini dinilai sangat terstruktur,
sistematis, dan massif, serta

berdampak langsung kepada kondisi fisik maupun psikis dari pihak yang menjadi korban. Pelanggaran HAM tersebut adalah Penyiksaan dan Perlakuan atau Penghukuman lain yang Kejam, Tidak Manusiawi, atau Merendahkan Martabat Manusia, atau disebut sebagai Penyiksaan. Penyiksaan menurut Christopher J. Einolf, yaitu ${ }^{1}$ :

"Is an act which severe physical pain is intentionally inflicted on a person by a public official while that person is under the custody or control of that official, where there has not been, or has not yet been, a formal finding of guilt".

Selain itu, Penyiksaan pun telah lama dijelaskan oleh Guazzini yang dikutip oleh James C. Welling. Hal ini dijelaskan sebagai berikut ${ }^{2}$ :

"What is called Torture is distress of body devised for extracting the truth. The Mode of administering torture by the use of rope was invented by the civil law, and this torment of the

\footnotetext{
${ }^{1}$ Christopher J. einolf, "The Fall and Rise of Torture : A Comparative and Historical Analisys", American Sociological Association, 1307 New York Aveneu NW, Washington, DC 20005-4701, 2007, hlm 103.

${ }^{2}$ James C. Weiling, "The Law of Torture : A Study in the Evolution of Law", American Anthropologist, Vol.5, No.3, 1892, hlm 198.
} 
rope, sometimes called the queen of torment, was justly invented by the civil law, as a mode of discovering truth, for the sake of the public welfare, to the end that crimes might not remain unpunished. It is called a species of evidence substituted to supply the lack of witnesses".

Kedua pakar tersebut menjelaskan secara berbeda terkait Penyiksaan, tetapi yang terpenting dari kedua pakar tersebut menguraikan bahwa Penyiksaan adalah tindakan yang dilakukan oleh Pejabat Publik dengan jalan kekerasan dalam rangka untuk mencari kebenaran agar sampai akhirnya kejahatan yang dilakukan oleh si korban tidak terjadi lagi.

Fenomena penyiksaan ini ternyata sudah menjadi fenomena global.Kita bisa melihat seksama bahwa ada banyak tipe-tipe penyiksaan itu, yang dilakukan oleh Negara melalui aparatusnya (Pejabat Publik).Biasanya terjadi pada saat situasi perang dan situasi kekerasan lainnya yang menyebabkan pertumpahan darah.Akan tetapi, penyiksaan juga dapat terjadi apabila individu atau kelompok yang berupaya untuk melakukan tindakan-tindakan yang dianggap subversif, yang dirasa oleh Pejabat Publik sebagai upaya untuk menggoyahkan status quo.

Menurut para pakar Ilmu Politik bahwa penyiksaan seringkali dianggap metode yang efektif dalam upaya mencari kebenaran oleh negaranegara non-democratic (tidak demokratis) atau negara-negara yang penguasanya memiliki gaya kepemimpinan yang sangat otoriter. Hal ini dilakukan dalam rangka untuk crushing opposition (menghancurkan lawan politik) dan memperluas terror kepada masyarakat luas agar tidak menggoyahkan status quo negaranegara tersebut. ${ }^{3}$ Dengan adanya fenomena tersebut, masyarakat internasional meyakini bahwa Penyiksaan merupakan pelanggaran HAM sebab pada dasarnyat setiap orang memiliki hak untuk menentukan sikap politiknya yang berbeda-beda.

\footnotetext{
${ }^{3}$ Jonathan Luke Austin dan Riccardo Bocco, "Becoming a torture : Towards a Global Ergonomics of Care", International Review of the Red Cross, 98 (3), 2016, hlm 864.
} 
Masyarakat internasional

membuat banyak sekali perjanjian internasional yang berkaitan dengan HAM dan salah satunya yaitu berkaitan dengan Penyiksaan, yang pada tanggal 10 Desember 1984 melalui Resolusi Majelis Umum PBB No.39/46 adalah Convention against Torture and Other Cruel, Inhuman or Degrading Treatment or Punishment (CAT) 1984. ${ }^{4}$ Dalam perjanjian internasional tersebut, berdasarkan pada Pasal 1, Penyiksaan merupakan:

"Any act by which severe pain or suffering, whether physically or mental, is intentionally inflicted on a person for such purposes as obtaining from him or a third person information or confession, punishing him for an act or a third person has committed or is suspected of having committed, or intimidating or coercing him or third person, or for any reason based on discrimination of any kind, when such pain or suffering is inflicted by or at the instigation of or with the consent or acquiescence of a public official or other person acting in an official capacity. It does not include pain or suffering arising only from, inherent in or incidental to lawful sanctions."

${ }^{4}$ Laode M. Sarif dkk, Jalan Panjang Penghapusan Penyiksaan, Jakarta : Kemitraan Partnership, Cet-2, 2012, hlm 2.
Penyiksaan dapat dikatakan sebagai setiap perbuatan yang dilakukan dengan sengaja sehingga menimbulkan rasa sakit atau penderitaan yang hebat, baik jasmani maupun rohani, pada seseorang untuk memperoleh pengakuan atau keterangan dari orang itu atau dari orang ketiga, dengan menghukumnya atas suatu perbuatan yang telah dilakukan atau diduga telah dilakukan oleh orang itu atau orang ketiga, atau mengancam atau memaksa orang itu atau orang ketiga, atau untuk suatu alasan yang didasarkan pada diskriminasi, apabila rasa sakit dan penderitaan tersebut ditimbulkan oleh, atas hasutan dari, dengan persetujuan, atau sepengetahuan pejabat publik. Hal itu tidak meliputi rasa sakit atau penderitaan yang timbul hanya dari, melekat pada, atau diakibatkan oleh sanksi hukum yang berlaku.

Berdasarkan penjelasan umum di atas dapatlah diketahui bahwa Penyiksaan merupakan pelanggaran HAM yang pelakunya adalah Pejabat Publik yang didasarkan pada 
diskriminasi atau untuk memperoleh informasi dan menimbulkan rasa sakit atau penderitaan, baik secara fisik maupun psikis daripada korban, sehingga dapat dikatakan bahwa dalam hukum internasional, penyiksaan tidak bisa dibenarkan dan dilarang berdasarkan pada hukum kebiasaan internasional, serta larangan terikat pada negara dan individu perihal penyiksaan itu sendiri. ${ }^{5}$

Pada konteks di Negara Indonesia, kasus-kasus mengenai Penyiksaan ini sudah banyak sekali. Kasus-kasus tersebut bahkan terjadi sejak memasuki masa Orde Baru hingga detik ini, sehingga perlu adanya implementing legislation atas konvensi anti penyiksaan ini di dalam hukum nasional Indonesia, sebab Indonesia adalah negara peserta dari Konvensi Anti Penyiksaan, dan telah meratifikasinya ke dalam UndangUndang No.5 Tahun 1998.

${ }^{5}$ Roger Douglas, Law, Liberty, and the Pursuit of Torture, University of Michigan Press, 2014, hlm 195.

\section{B. METODE PENULISAN}

Metode penulisan yang
digunakan adalah didasarkan pada
pendekatan yuridis normatif yaitu
metode yang mengutamakan cara
meneliti bahan pustaka yang disebut
data sekunder6 dan dilakukan secara
deskriptif-analitis, yakni dengan
menggunakan fakta-fakta mengenai
objek yang akan ditulis, kemudian
dilakukan analisis data berdasarkan
data kepustakaan yang merupakan data
sekunder untuk mendapatkan
kesimpulan yang selanjutnya akan
disampaikan secara kualitatif.

\section{HASIL DAN PEMBAHASAN}

\section{Asas Yurisdiksi Universal}

Terkait Asas Yurisdiksi Universal, hal ini tidak bisa dilepaskan dari pengertian Yurisdiksi itu sendiri. Yurisdiksi menurut DJ Harris merupakan kekuasaan negara di bawah hukum internasional untuk mengatur individu dan benda hak milik melalui

${ }^{6}$ Soerjono Soekanto dan Sri Mamudji, Penelitian Hukum Normatif, Jakarta : Rajawali Press, 2014, hlm 14.

${ }^{7}$ Ibid., hlm 62. 
hukum nasional.Kekuasaan ini meliputi kekuasaan presktriptive dan kekuasaan untuk menegakkan.Dalam konsep hukum pidana dikenal berbagai macam konsep yurisdiksi. Pertama adalah Yurisdiksi Teritorial, yaitu suatu cara menentukan yurisdiksi dengan melihat kepada tempat di mana pelaku menjalankan perbuatannya. Kedua, yurisdiksi dengan mendasarkan kepada nasionalitas atau karakter nasional dari individu yang melakukan perbuatan.Ketiga adalah yurisdiksi dengan mendasarkan kepada prinsip protektif di mana dalam menentukan yurisdiksi dengan melihat kepada kepentingan nasional yang dilukai pelaku. Keempat adalah yurisdiksi nasional pasif yang melihat kepada nasionalitas korban serta terakhir adalah Yurisdiksi Universal, yakni ${ }^{8}$ :

"Universal Jurisdiction is criminal jurisdiction based solely on the nature of the crime without regard to where the crime was commited, the nationality of the alleged or

${ }^{8}$ Johanes Irawan, Pelaksanaan Yurisdiksi Universal dalam Kedaulatan Nasional Negara-Negara (Kumpulan Ketentuan dan Praktik Kasus di Berbagai Negara), Depok : Rajawali Pers, 2018, hlm 9-10. convictedperpetrator, the nationality of the victim or any other connection to the state exercising such jurisdiction."

\section{Asas Yurisdiksi Universal} didasarkan pada sifat kejahatan tanpa memperhatikan di mana kejahatan itu dilakukan, kewarganegaraan pelaku yang dituduh atau dihukum, kewarganegaraan korban atau koneksi lainnya dengan negara yang menggunakan yurisdiksi tersebut, yang berarti bahwa kejahatan tersebut didasarkan kepada kesepakatan masyarakat internasional melalui perjanjian internasional bahwa kejahatan tersebut mengancam masyarakat internasional.

Pada asas ini pula bahwa setiap negara mempunyai yurisdiksi terhadap kejahatan yang mengancam masyarakat internasional.Asas ini lahir dikarenakan tidak ada badan peradilan yang khusus mengadili orang perorangan.Kejahatan yang telah diterima sebagai kejahatan yang tunduk kepada Yurisdiksi Universal 
adalah pembajakan dan kejahatan perang. ${ }^{9}$

\section{Implementing Legislation}

Di dalam teori monisme, khususnya teori monisme primat hukum internasional, terdapat istilah yang disebut sebagai Implementing Legislation.Implementing Legislation merupakan penerapan di mana legislasi nasional sebelumnya telah mengatur masalah yang sama dengan yang diatur di dalam hukum internasional. Perjanjian internasional yang berkaitan dengan Implementing Legislation bisa dianggap sebagai bentuk dari standard/harmonizedsetting treaties, di mana wilayah dari penegakkan perjanjian tersebut ada pada wilayah hukum nasional karena menyangkut kepentingan hukum warga negara sebagai subjek hukum ketimbang kepentingan negara pihak vis a vis negara lain. Konsekuensinya adalah meskipun pihak negara mengikuti teori monisme (primat hukum internasional), maka tetaplah membutuhkan hukum nasional untuk

${ }^{9}$ Ibid., hlm 17-18. melaksanakannya. Biasanya jenis perjanjian ini tidak menciptakan norma yang dimaksud, namun hanya mewajibkan negara untuk menciptakan norma itu di dalam hukum nasionalnya. ${ }^{10}$

Hal ini sejalan dengan pendapat I Wayan Parthiana bahwa ketentuan dalam perjanjian internasional dapat pula diadopsi langsung oleh pembuat undangundang Indonesia dan dengan itu seketika menjadi bagian dari hukum nasional.Pengadopsian ini bisa dilakukan terhadap seluruh, sebagian, atau beberapa ketentuan dari perjanjian internasional tersebut ${ }^{11}$, yang diimplemetasikan dalam legislasi nasional (undang-undang).

10 Damos Dumoli Agusman, Hukum Perjanjian Internasional Kajian Teori dan Praktik Indonesia, Bandung : Refika Aditama, Cet-2, 2014, hlm 100.

11 I Wayan Parthiana, "Beberapa Masalah Dalam Pengimplementasian Kewajiban Negara Indonesia di Bawah Perjanjian Internasional ke Dalam Hukum Nasional Indonesia", Veritas et Justitia Journal Unpar, Vol.3, No.1, 2014, hlm 171. 


\section{Penyiksaan yang Terjadi di penyimpangan narkoba oleh korban di Indonesia \\ Medan, tanggal 24 Maret 2014. ${ }^{12}$}

Banyak sekali kasus-kasus

Kasus-kasus lain yang sangat yang berkaitan dengan Penyiksaan ini dan sudah ada sejak lama yaitu sejak memasuki masa Orde Baru hingga detik ini, tetapi kasus-kasus yang akan dipaparkan di sini adalah kasus-kasus yang terkini. Kasus pertama yakni yang dialami oleh Anandar (27), di Palu, Sulawesi Tengah, pada tanggal 10 November 2013.Korban dijemput paksa oleh anggota Polisi dari rumahnya terkait dugaan kasus Kekerasan dalam Rumah Tangga (KDRT).Korban menuturkan, dirinya sempat disengat aliran listrik oleh anggota Polisi ketika diangkut ke dalam kendaraan operasional dari rumahnya menuju Mapolres Palu. Kasus kedua yakni yang dialami oleh Rizki Siregal (19), mahasiswa Ekonomi Universitas Sumatera Utara (USU), mengaku sempat mengalami pemukulan serta diestrum terkait

menarik untuk diketahui sepanjang 2019, Pertama yaitu kasus Penyiksaan yang terjadi tanggal 1 Mei 2019 pada saat Hari Buruh Internasional (International Labour Day atau May Day) di Kota Bandung. Pada saat itu terdapat segerombolan orang yang mengaku dirinya sebagai kelompok Anarko-Sindikalis yang sedang memperjuangkan hak-hak buruh dan penolakan atas sistem ekonomi kapitalisme, lalu mengalami represi dari Aparat Negara (Polisi, dengan menurunkan Prabu, Brimob, bahkan melibatkan TNI) yang mana hanya karena sebagian anggota dari kelompok Anarko-Sindikalis telah melakukan tindakan Vandalisme dan merusak Fasilitas Umum. Terdapat sekitar 612 orang yang ditangkap yang dianggap sebagai penyusup.Setelah itu, Polisi dan TNI melakukan

\footnotetext{
${ }^{12}$ Laporan Praktik Penyiksaan dan Perbuatan Tidak Manusiawi Lainnya di Indonesia 20132014, Penyiksaan : Angka Penyiksaan Meningkat, Aktor Semakin Meluas, Jakarta : KontraS, hlm 23.
} 
Penyiksaan kepada para korban seperti pengundulan,

penelanjangan, pemukulan dalam berbagai bentuk, bahkan mencoreti tubuh dari para anggota kelompok tesebut, dan dibawa ke Mapolrestabes Bandung. ${ }^{13}$

Kasus selanjutnya adalah kasus yang dialami oleh Luthfi (20) sang pembawa bendera merah putih pada saat setelah ditangkap oleh Aparat Negara (Polisi) pada masa aksi besarbesaran Reformasi Dikorupsi bulan September 2019 di Jakarta. Selama penahanan di Polres Jakarta Barat yang berlansung selama tiga hari, ia mengalami berbagai macam penyiksaan yang dilakukan oleh Polisi untuk mendapatkan keterangan yang sesuai dengan unsur tindak pidana yang akan didakwakan. Bentuk penyiksaan yang dilakukan oleh Polisi kepadanya adalah pemukulan, diestrum listrik di bagian telinga, ditendang, dan kepala ditutupi dengan

${ }^{13}$ Redaksi Buruh.co, Serangan ke Massa Aksi May Day Tandakan Turunnya Demokrasi, Buruh.co, https://buruh.co/serangan-ke-massaaksi-may-day-tandakan-turunnya-demokrasi/, diakses pada tanggal 5 Februari 2020, Pukul 14.15 WIB.
plastik.Keseluruhan tindakan

penyiksaan tersebut dilakukan karena Luthfi menjawab tidak sesuai dengan keterangan yang diinginkan oleh Polisi. $^{14}$

\section{Pengaturan Hukum Pidana}

\section{Penyiksaan di Indonesia, Perlukah?}

Dari beberapa kasus yang telah dipaparkan dapatlah diketahui bahwa Penyiksaan masih terjadi di Indonesia hingga detik ini, sehingga diperlukanlah pengaturan hukum di Indonesia yang menjadikan Penyiksaan sebagai Tindak Pidana berdasarkan Konvensi Anti Penyiksaan.

Negara Indonesia pernah diberikan rekomendasi oleh Komite Menentang Penyiksaan agar melakukan kriminalisasi atas penyiksaan dalam sistem hukum domestiknya.Menanggapi hal itu, pemerintah Indonesia menyatakan bahwa hal itu tidak perlu karena

\footnotetext{
${ }^{14}$ Haris Azhar, Siaran Pers: "Peradilan Sesat untuk Luthfi,https://lokataru.id/siaran-persperadilan-sesat-untuk-luthfi/, diakses pada tanggal 5 Februari 2020, Pukul 14.31 WIB.
} 
Indonesia telah memiliki KUHP yang telah mengatur tentang larangan penganiayaan (Pasal 351-358 serta Pasal 422 KUHP). ${ }^{15}$

Persoalannya adalah bahwa di dalam KUHP, tidak terdapat unsurunsur yang tercakup perihal penyiksaan, misalnya untuk memperoleh informasi atau melakukan tindakan diskriminasi dan unsur yang status para pelakunya yang merupakan pejabat atau bertindak dalam kapasitas sebagai Pejabat Publik. Akibatnya, pengadilan pun gagal menempatkan tindakan tersebut sebagai sebuah kejahatan penyiksaan dan proses peradilan hanya menempatkan mereka sebagai pelaku sebagaimana warga negara biasa. Pengadilan tidak mampu memberikan pembobotan lebih atas posisi para terdakwa dan menguraikan kemungkinan keterlibatan pihak lain misalnya atasan mereka, sehingga

${ }^{15}$ Eko Riyadi, Hukum Hak Asasi Manusia Perspektif Internasional, Regional, dan Nasional,Depok : Rajawali Pers, 2018, hlm 137. hanya dianggap sebagai tindak pidana penganiayaan. ${ }^{16}$

Padahal Negara Indonesia adalah salah satu negara yang menjadi negara peserta pada Convention against Torture and Other Cruel, Inhuman or Degrading Treatment or Punishment (CAT) 1984 dan telah diratifikasi ke dalam Undang-Undang No.5 Tahun 1998. Namun, perjanjian internasional tersebut bersifat Non-Self Executing yang berarti bahwa perjanjian internasional tersebut mewajibkan negara-negara peserta untuk membuat produk hukum yang didasarkan pada perjanjian internasional tersebut, yang oleh karenanya Indonesia harus melakukan Implementing Legislation atas pengaturan terkait Penyiksaan agar negara Indonesia memiliki produk hukum tersendiri terkait pelarangan atas Penyiksaan.

Negara Indonesia mesti melakukan implementing

${ }^{16}$ Zainal Abidin, Tindak Pidana Penyiksaan dalam RKUHP, Jakarta : Institute for Criminal Justice Reform (ICJR), 2017, hlm 23. 
legislationatas Konvensi Anti

Penyiksaan sebagaimana didasarkan pada Konvensi tersebut, yakni ${ }^{17}$ :

"Each State Party shall take effective legislative, administrative, judicial or other measures to prevent acts of torture in any territory under its jurisdiction."

Negara peserta pun mesti memberi jaminan bahwa tindakan penyiksaan merupakan pelanggaran hukum di wilayahnya. Ini didasarkan pada Konvensi, yaitu:

"Each state Party shall ensure that acts of torture are offences under its criminal law. The same shall apply to an attempt to commit torture and to an act by any person which constitutes complicity or participation in torture ${ }^{18}$ and Each State Party shall make these offences punishable by appropriate penalties which take into account their grave nature. ${ }^{19}$,"

Dalam Undang-Undang No.5

Tahun 1998 tentang Pengesahan Convention against Torture and Other Cruel, Inhuman or Degrading Treatment or Punishment (CAT) 1984, Negara Indonesia menjadi negara

${ }^{17}$ Article 2 (1) Convention against Torture and Other Cruel, Inhuman or Degrading Treatment or Punishment (CAT) 1984.

18 Article 4 (1)

19 Article 4 (2) peserta didasarkan pada alasan sebagai berikut :

1. Pancasila sebagai falsafah dan pandangan hidup bangsa Indonesia dan Undang-Undang Dasar 1945 sebagai sumber dan landasan hukum nasional, menjunjung tinggi harkat dan martabat manusia seperti tercermin dalam Sila Kemanusiaan yang Adil dan Beradab. Asas ini merupakan amanat konstitusional bahwa bangsa Indonesia bertekad untuk mencegah dan melarang segala bentuk penyiksaan, sesuai dengan isi konvensi ini.

2. Dalam rangka pengamalan Pancasila dan pelaksanaan Undang-Undang Dasar 1945, Indonesia pada dasarnya telah menetapkan peraturan perundang-undangan yang langsung mengatur pencegahan dan pelarangan, segala bentuk penyiksaan yang tidak manusiawi dan merendahkan martabat manusia. Namun 
perundang-undangan itu karena belum sepenuhnya sesuai dengan konvensi, masih perlu disempurnakan.

3. Penyempurnaan perundangundangan nasional tersebut, akan meningkatkan perlindungan hukum secara lebih efektif, sehingga akan lebih menjamin hak-hak setiap warga negara bebas dari penyiksaan dan perlakuan atau penghukuman lain yang kejam, tidak manusiawi atau merendahkan martabat manusia, demi tercapainya suatu masyarakat Indonesia yang tertib, teratur, dan berbudaya.

4. Suatu masyarakat Indonesia yang tertib, teratur, dan berbudaya akan mampu mewujudkan upaya bersama untuk memelihara perdamaian, ketertiban umum, dan kemakmuran dunia serta melestarikan peradaban umat manusia.
5. Pengesahan dan pelaksanaan isi Konvensi secara bertanggungjawab menunjukkan kesungguhan Indonesia dalam upaya pemajuan dan perlindunga HAM , khususnya hak bebas dari penyiksaan. Hak ini juga akan lebih meningkatkan citra positif Indonesia di dunia Internasional dan memantapkan kepercayaan masyarakat internasional terhadap Indonesia.

Dapat kita pahami bahwa dengan mengetahui alasan-alasan tersebut, memang sepantasnya negara Indonesia mesti melakukan Implementing Legislation atas Konvensi Anti Penyiksaan agar tidak terus menerus Penyiksaan terjadi kepada masyarakat oleh Aparat Negara (Polisi). 
Penerapan Asas Yurisdiksi yaitu Questions relating to the Universal dalam Hukum Penyiksaan di Indonesia

Persoalan mengenai

Penyiksaan, di mana negara Indonesia telah meratifikasiConvention against Torture and Other Cruel, Inhuman or Degrading Treatment or Punishment (CAT) 1984 dan telah diratifikasi ke dalam Undang-Undang No.5 Tahun 1998 menjadi sebuah kewajiban untuk melakukan Implementing Legislation atas Konvensi tersebut. Sebab, konvensi tersebut menerapkan Asas Yurisdiksi Universal, sehingga tidak semata-mata bahwa Penyiksaan hanya persoalan hukum pidana di dalam negeri saja, tapi sudah menjadi kejahatan internasional, di mana masyarakat internasional menganggap tindakan itu sebagai ancaman yang luar biasa.

Hal tersebut didasarkan kepada satu kasus yang menjadi landmark bahwa penyiksaan merupakan kejahatan internasional dan asas hukum yang digunakan adalah asas yurisdiksi universal.Kasus tersebut Obligation to Prosecute or Extradite (Belgium v. Senegal).Kasus ini dilatarbelakangi dengan terpilihnya Hissane Habre sebagai Presiden Republik Chad pada tanggal 7 Juni 1982. Selama menjabat, ia diduga telah melakukan pelanggaraan HAM berat seperti penangkapan atas politisi oposisi, penghukuman tanpa pengadilan dan perlakuan manusiawi, dan lain-lain. Tanggal 1 Desember 1990, Hissane Habre meminta suaka politik ke Senegal dan saat itu pula ia menetap di Dakar, ibu kota Senegal. Tanggal 25 Januari 2000, Belgia menggugat Senegal agar segera menghukum Hissane Habre karena telah melakukan kejahatan kemanusiaan di negaranya pada saat ia dulu menjadi Presiden, lalu pada tanggal 19 September 2005, hakim penyelidik menemukan pelanggaran kemanusiaan, penyiksaan, genosida, sehingga Belgia mengaajukan ekstradisi atas Hissane Habre kepada Senegal. Tanggal 25 November 2005 putusan pengadilan Chambre d'accusation oleh Dakar Court of 
Appeal menjawab tentang pengajuan ekstradisi yang diajukan oleh Belgia terhadap Hissane Habre.Hasil putusan tersebut yakni Senegal tidak memiliki kewajiban untuk melakukan ekstradisi atas investigasi terhadap kejahatan yang telah dilakukan oleh Hissane Habre berkenaan dengan tidak diaturnya ketentuan tersebut di dalam aturan hukum pidana dan konstitusi Senegal. ${ }^{20}$

Belgia tidak menerima atas putusan tersebut dan bersepakat untuk menyelesaikan perkara tersebut ke Mahkamah Internasional. Pada tahun 2012, Hakim Mahkamah Internasional membuat putusan bahwa Senegal bersalah atas tindakannya yang tidak melakukan penyelidikan dan proses mengadili Hissane Habre atas pelanggaraan HAM beratnya, yang di dalamnya terdapat tindakan Penyiksaan serta tidak melakukan ekstradisi terhadap Hissane Habre kepada negara lain untuk mengadili

${ }^{20}$ Summary of the Judgment concerning Questioning relating to the Obligation to Prosecute or Extradite (Belgium v. Senegal), International Court of Justice, 20 July 2012, hlm 1-2. dan Senegal telah melanggar hukum kebiasaan internasional. $^{21}$

Putusan tersebut didasarkan pada Pasal 6 ayat (2) Konvensi Anti Penyiksaan yang menyatakan bahwa suatu negara yang mempunyai tersangka yang telah melakukan Pelanggaran HAM berat seperti Penyiksaan, maka negara tersebut harus segera membuat penyelidikan awal berdasarkaan fakta yang ada agar bisa dibawa ke otoritas yang berwenang untuk mengadili. Pasal tersebut bermakna bahwa proses hukum tersebut sesuai dengan asas yurisdiksi universal, dan berdasarkan Pasal 7 ayat (1) Konvensi Anti Penyiksaan bahwa negara pihak yang wilayah kewenangan hukumnya ditemukan seseorang yang diduga telah melakukan pelanggaran demikian, jika negara tersebut tidak melakukan ekstradisi, maka harus mengajukan kasus tersebut kepada pihak yang berwenang untuk tujuan penuntutan. ${ }^{22}$ Dalam hal ini, Senegal

${ }^{21}$ Ibid., hlm 15

${ }^{22}$ Ibid., hlm 14. 
adalah negara peserta dari Konvensi Anti Penyiksaan, sehingga negara tesebut seharusnya melakukan penyelidikan dan penututan atas Hissane Habre, tetapi ternyata tidak diindahkan oleh Senegaal.Oleh karena itu, Belgia berhak untuk melakukan penyelidikan dan penuntutan karena Belgia bersedia untuk melakukannya dan mendaku sebagai negara yang netral.

\begin{tabular}{lrr}
\multicolumn{2}{c}{ Berdasarkan kasus tersebut } \\
dapatlah & diketahui & bahwa \\
Implementing & Legislation & atas
\end{tabular}

Konvensi Anti Penyiksaan di negara Indonesia harus dilakukan, sebab jika tidak demikian, para pelaku yang terduga melakukan Penyiksaan, jika yang bersangkutan pergi ke luar negeri (bukan dengaan tujuan untuk urusan kenegaraan), maka pelaku tersebut yang merupakan Pejabat Publik, akan tertangkap oleh otoritas negara lain yang juga merupakan negara peserta konvensi tersebut. Di sini lah asas yurisdiksi universal diterapkan agar kasus-kasus kejahatan di dalamnya terdapat penyiksaan dapat diselidiki dan dituntut berdasarkan hukum nasional Indonesia.

\section{PENUTUP}

\section{Kesimpulan}

Negara Indonesia sebagai negara peserta dari Convention against Torture and Other Cruel, Inhuman or Degrading Treatment or Punishment (CAT) 1984 harus melakukan Implementing Legislation dari konvensi tersebut ke dalam hukum nasional Indonesia untuk mengatur tentang pemidanaan Penyiksaan. Hal ini didasarkan pada alasan negara Indonesia untuk mengikatkan diri dengan konvensi tersebut di dalam Undang-Undang No.5 Tahun 1998 yang pada intinya yakni tidak ada pertentangan dengan Pancasila sebagai falsafat bangsa dan menjunjung tinggi harkat dan martabat manusia.

Jika tidak segera dilakukan Implementing Legislation oleh negara Indonesia terkait konvensi tersebut, maka ada kekhawatiran bahwa pelaku yang terduga melakukan tindakan Penyiksaan akan dipidanakan oleh 
otoritas negara lain yang juga merupakan negara peserta konvensi tersebut sebab terdapat penerapan asas yurisdiksi universal dalam konvensi tersebut dengan berkaca kepada kasus Questions relating to the Obligation to Prosecute or Extradite (Belgium $v$. Senegal), sehingga dapat dikatakan bahwa tindakan Penyiksaan merupakan kejahatan internasional sebab mengancam masyarakat internasional.

\section{Saran}

Dalam hal melakukan
Implementing Legislation atas
konvensi anti penyiksaan oleh negara Indonesia ke dalam hukum nasional Indonesia, dibuatlah dalam bentuk undang-undang tersendiri dan tidak perlu disatukan ke dalam Rancangan Kitab Undang-Undang Hukum Pidana (RKUHP), sebab Penyiksaan merupakan tindak pidana khusus yang pelakunya adalah Pejabat Publik yang sesuai dengan Pasal 1 ayat (1) konvensi tersebut. 


\section{DAFTAR PUSTAKA}

\section{Buku dan Jurnal}

Damos Dumoli Agusman, Hukum Perjanjian Internasional Kajian Teori dan Praktik Indonesia, Bandung : Refika Aditama, Cet-2, 2014.

Douglas, Roger, Law, Liberty, and the Pursuit of Torture, University of Michigan Press, 2014.

Eko Riyadi, Hukum Hak Asasi Manusia Perspektif Internasional, Regional, dan Nasional,Depok : Rajawali Pers, 2018.

I Wayan Parthiana, "Beberapa Masalah Dalam Pengimplementasian Kewajiban Negara Indonesia di Bawah Perjanjian Internasional ke Dalam Hukum Nasional Indonesia", Veritas et Justitia Journal Unpar, Vol.3, No.1, 2014.

J. einolf, Christopher, "The Fall and Rise of Torture : A Comparative and Historical Analisys", American Sociological Association, 1307 New York Aveneu NW, Washington, DC 20005-4701, 2007.

James C. Weiling, "The Law of Torture : A Study in the Evolution of Law", American Anthropologist, Vol.5, No.3, 1892.

Johanes Irawan, Pelaksanaan Yurisdiksi Universal dalam Kedaulatan Nasional Negara-Negara (Kumpulan Ketentuan dan Praktik Kasus di Berbagai Negara), Depok : Rajawali Pers, 2018.

Laode M. Sarif dkk, Jalan Panjang Penghapusan Penyiksaan, Jakarta : Kemitraan Partnership, Cet-2, 2012.

Luke Austin, Jonathan dan Riccardo Bocco, "Becoming a torture : Towards a Global Ergonomics of Care", International Review of the Red Cross, 98 (3), 2016. 
Soerjono Soekanto dan Sri Mamudji, Penelitian Hukum Normatif, Jakarta : Rajawali Press, 2014.

Zainal Abidin, Tindak Pidana Penyiksaan dalam RKUHP, Jakarta : Institute for Criminal Justice Reform (ICJR), 2017.

\section{Sumber Kasus}

Haris Azhar, Siaran Pers: "Peradilan Sesat untuk Luthfi, https://lokataru.id/siaranpers-peradilan-sesat-untuk-luthfi/, diakses pada tanggal 5 Februari 2020, Pukul 14.31 WIB.

Laporan Praktik Penyiksaan dan Perbuatan Tidak Manusiawi Lainnya di Indonesia 2013-2014, Penyiksaan : Angka Penyiksaan Meningkat, Aktor Semakin Meluas, Jakarta : KontraS.

Redaksi Buruh.co, Serangan ke Massa Aksi May Day Tandakan Turunnya Demokrasi, Buruh.co, https://buruh.co/serangan-ke-massa-aksi-may-daytandakan-turunnya-demokrasi/, diakses pada tanggal 5 Februari 2020, Pukul 14.15 WIB.

Summary of the Judgment concerning Questioning relating to the Obligation to Prosecute or Extradite (Belgium v. Senegal), International Court of Justice, 20 July 2012.

\section{Sumber Hukum}

Convention against Torture and Other Cruel, Inhuman or Degrading Treatment or Punishment (CAT) 1984.

Undang-Undang No.5 Tahun 1998 tentang Pengesahan Convention against Torture and Other Cruel, Inhuman or Degrading Treatment or Punishment (CAT) 1984. 